\title{
Clinicopathological characteristics of intracranial meningiomas
}

\author{
Rajiv Jha $M C^{1}$, Prakash Bista $M C h^{2}$ \\ ${ }^{1}$ National Neurosurgical Referral Center, NAMS Bir Hospital, Kathmandu, Nepal, ${ }^{2}$ National Neurosurgical Referral Center, \\ Bir Hospital, Kathmandu, Nepal
}

Date of submission: $26^{\text {th }}$ May 2020

Date of acceptance: $15^{\text {th }}$ July 2020

Date of publication: $12^{\text {th }}$ August 2020

\section{Abstract}

Background: Meningioma comprises $25-30 \%$ of total central nervous system tumors detected. Ninety percent of meningiomas are benign, $6 \%$ are atypical, and $2 \%$ are malignant. Complete resection is often curative.

Objectives: The objective of this study is to give ideas about the descriptive epidemiology, clinical presentation and histopathology of current scenario at National Neurosurgical Referral Center, Nepal.

Methods: This is a prospective study from the period of January 2015 to September 2019 in the department of neurosurgery, National Academy of Medical Science, Bir Hospital. Inclusion criteria consists of all the histopathological proven cases of meningioma during the study period.

Result: A total of 150 meningioma cases were operated during the study period. The average age of presentation was 42 years. Male to female ratio was 1:2. Most common affected age group was 30-50 years. The most common clinical symptoms for intracranial meningioma were headache followed by vomiting and paresis. Among intracranial meningioma, the most common location was convexity meningioma followed by sphenoid wing meningiomas and parasagittal meningiomas. Most common histopathological variety encountered was transitional meningioma, World health organization grade I.

Conclusion: Meningiomas are slow growing, extra-axial tumor, usually benign which are most commonly located along convexities, sphenoid ridge and parasagittal area. Most are cured if completely removed, which is not always possible.

Key words: Central nervous system tumor, Diagnosis, Histopathology, Meningioma

\section{Introduction}

\section{Access this article online}

Website: https://www.nepjol.info/index.php/NJN

DOI: https://doi.org/10.3126/njn.v17i2.30181

HOW TO CITE

Jha R, Bista P. Clinicopathological characteristics of intracranial meningiomas. NJNS. 2020;17(2):16-25

${ }^{1}$ ORCID iD: https://orcid.org/0000-0002-2830-7835

${ }^{2}$ ORCID iD: https://orcid.org/0000-0002-4811-6964

Address for correspondence:

Dr. Rajiv Jha

Professor of Neurosurgery

National Neurosurgical Referral Center

NAMS Bir Hospital

Kathmandu, Nepal

Contact number: +9779851039699

E-mail: medrajiv18@hotmail.com

Copyright (C) 2020 Nepalese Society of Neurosurgeons (NESON)

ISSN: 1813-1948 (Print), 1813-1956 (Online)

\section{(i) (8)}

This work is licensed under a Creative Commons Attribution-Non Commercial 4.0 International License.
Tntracranial meningiomas account for $25-30 \%$ of all Lprimary intracranial tumors. They originate from the arachnoid cap cells and occur in middle-aged adults. Women are affected twice as often as men. Meningiomas are mostly well-differentiated, benign, and encapsulated lesions that indent the brain as they enlarge. Although most meningiomas are benign, they have a surprisingly broad spectrum of clinical characteristics, and histologically distinct subsets are associated with a high risk of recurrence, even after seemingly complete resection. In rare instances, meningiomas are malignant. Most meningiomas are iso-intense to the brain on T1- and T2-weighted images. ${ }^{1}$

Meningioma accounted for more than a third of all primary central nervous system tumors reported in the US between 2006 and 2010, where the highest incidence rate $(7.44$ per 100,000$)$ of the disease has been recorded. ${ }^{2}$ Meningiomas usually grow slowly, with a long initial asymptomatic phase, and may remain 


\section{Clinicopathological characteristics of intracranial meningiomas}

silent until the patient's sudden death. ${ }^{3}$ Only 3\%-6\% of clinically detected asymptomatic meningiomas later become symptomatic. ${ }^{4}$ When symptomatic, intracranial meningiomas present a wide variety of symptoms arising from the compression of adjacent structures, direct invasion of or reactive changes in the adjacent brain tissue, and obstruction of cerebrospinal fluid pathways, cortical veins, or major venous sinuses. ${ }^{5}$ Symptoms and signs may include seizure disorders, raised intracranial pressure sign, classic early morning headaches, focal neurological deficits, such as motor and sensory disorders, ataxia, language dysfunction, cranial neuropathies, psychomotor symptoms, and behavioral disturbances. ${ }^{5}$

The purpose of our study was to evaluate the demographics, clinical presentation, radiological findings, extent of surgery, histological findings, overall outcome and recurrence rates over the past 5 years at our institution.

\section{Methods and Materials}

This is a prospective study of intracranial meningiomas, carried out at National Neurosurgical Referral Center (NNRC), National Academy of Medical Sciences (NAMS) Bir hospital. Institutional review board (IRB) approval was taken from the hospital for the study. Consent was taken from the patients if they were able to communicate and from the next of kin if they were not able to give consent. All histopathological proven intracerebral meningioma in this department were included in this study. The duration of the study was from January 2015 to September 2019 (for 55 months). Age, sex, clinical presentations and neurological manifestations were noted. Outcome measured on the basis of extent of tumor excision, histopathological types, recurrence and Glasgow Outcome Scale (GOS) at 6 months.

\section{Results}

Total number of intracranial meningioma operated was 150 . The average age of presentation was 42 years. Female were twice more affected than males. Most common affected age group was 30-50 years. Females were involved at a slightly younger age compared to the male. The most common clinical symptoms for intracranial meningioma were headache followed by vomiting and paresis (Table 1).

\begin{tabular}{l|l}
\hline Clinical Presentation & Number of patients \\
\hline Headache & $134(89 \%)$ \\
\hline Vomiting & $96(64 \%)$ \\
\hline Seizure & $46(31 \%)$
\end{tabular}

\begin{tabular}{l|l}
\hline Paresis & $45(30 \%)$ \\
\hline Visual impairment & $42(28 \%)$ \\
\hline Ataxia & $29(19 \%)$ \\
\hline Aphasia & $25(17 \%)$ \\
\hline Personality change & $23(15 \%)$ \\
\hline Diplopia & $22(14.6 \%)$ \\
\hline Vertigo & $21(14 \%)$ \\
\hline Decreased level of consciousness & $18(12 \%)$ \\
\hline Decreased hearing & $18(12 \%)$ \\
\hline
\end{tabular}

Table 1: Clinical Presentation of Intracranial Meningioma

Common neurological examination findings were papilledema, paresis and cranial nerve deficit (Table 2).

\begin{tabular}{l|l}
\hline Clinical findings & \multicolumn{1}{c}{ Number of patients } \\
\hline Papilledema & $97(65 \%)$ \\
\hline Paresis & $56(37 \%)$ \\
\hline Cranial nerve deficit & $47(31 \%)$ \\
\hline Memory impairment & $33(22 \%)$ \\
\hline Visual field deficit & $23(15 \%)$ \\
\hline Decreased hearing & $23(15 \%)$ \\
\hline Nystagmus & $22(15 \%)$ \\
\hline Paresthesia & $18(12 \%)$ \\
\hline Altered level of consciousness & $18(12 \%)$ \\
\hline Normal finding & $18(12 \%)$ \\
\hline Aphasia & $17(12 \%)$ \\
\hline
\end{tabular}

Table 2: Clinical findings in Intracranial Meningioma

Among intracranial meningioma, the most common location was convexity meningioma followed by sphenoid wing meningiomas and parasagittal meningiomas (Table 3).

\begin{tabular}{ll}
\hline Convexity & $36(24 \%)$ \\
\hline Para-sagittal & $29(19 \%)$ \\
\hline Sphenoid wing & $28(19 \%)$ \\
\hline Cerebellopontine angle & $9(6 \%)$ \\
\hline Tuberculum sella & $8(5 \%)$ \\
Olfactory groove & $8(5 \%)$ \\
\hline Falx & $7(4.6 \%)$ \\
\hline Lateral ventricle & $5(3 \%)$ \\
\hline Tent & $5(3 \%)$ \\
Petroclival & $5(3 \%)$ \\
\hline Foramen magnum & $3(2 \%)$ \\
Cerebellar convexity & $3(2 \%)$ \\
\hline Pineal Region & $2(1 \%)$ \\
\hline Intra orbital & $2(1 \%)$ \\
\hline
\end{tabular}

Table 3: Location of intracranial meningioma 


\section{Jha et al}

Contrast enhanced CT scan and MRI Brain is the standard of diagnosis. In CT scan most meningioma enhanced avidly and nearly all enhanced at least in part, even if heavily calcified. (Figure 1, Table 4)

\begin{tabular}{l|l}
\hline CT finding & Number of patients \\
\hline Homogenous enhancement & $88(59 \%)$ \\
\hline Heterogenous Enhancement & $62(41 \%)$ \\
Calcification & $68(45 \%)$ \\
Hyperostosis & $52(35 \%)$ \\
Mass effect/Midline shift & $122(81 \%)$ \\
\hline
\end{tabular}

Table 4: CT scan findings in intracranial meningioma

On MRI, meningiomas were usually hypo- to isointense relative to the cerebral cortex on T1-weighted sequences and iso- to hyper intense on T2-weighted sequences (Figure 2).

Digital subtraction angiogram (DSA) remained a useful tool in giant meningiomas not only to embolize the lesion but also to treat tumor associated vascular malformation and to achieve the full knowledge of vascular anatomy. (Figure 3)

Although total removal can provide a cure for meningioma, it is not always possible. The tumor location determines how much can be safely removed. Decision to extent of resection also depends on consistency and vascularity of the tumor (Figures 4, 5).

If some tumor is left attached to arteries or nerves, radiation can treat the remainder. The risks of surgery also depend on where the tumor is located. In most of the meningiomas surgery started with debulking of the tumor, and all convexity, parasagittal, and falx meningioma needed duroplasty as dura was also excised in toto with the tumors (Figures 6,7).

In those cases where dura couldn't be excised, was coagulated at the attachments (Figure 8).

Intra operative blood loss was also very less and tumor consistency were found to be slightly softer compared to non-embolized meningiomas. About 70 percent (105 cases) of the meningioma had size more than $3 \mathrm{~cm}$ and 14 percent were more than $5 \mathrm{~cm}$ size. Meningioma less than $5 \mathrm{~cm}$ size had less blood loss and morbidity while more than $5 \mathrm{~cm}$ sized needed blood transfusion in majority of the cases with increased morbidity. Major blood vessels engulfing the tumor was commonly seen in clinoidal meningioma followed by olfactory groove meningiomas. Consistency of meningiomas differed, majority had firm consistency where cavitron ultrasonic surgical aspirator (CUSA) (which was used in all cases) was not of much help. CT scan and MRI brain image could not reliably predict consistency of meningioma in our study.
Ninety two percent (138 cases) of the meningiomas were excised completely, and partially excised meningiomas were further treated according to the histopathology grade (Table 5).

\begin{tabular}{ll}
\hline Convexity & All Simpson Grade I Excision \\
\hline Para-sagittal & Total Excision \\
\hline Sphenoid wing & Total Excision \\
\hline Tuberculum sella & Total Excision \\
\hline Olfactory groove & Total Excision \\
\hline Lateral ventricle & Total Excision \\
\hline Tent & Total Excision \\
\hline Cerebellopontine & Total Excision \\
angle & Total/Subtotal Excision \\
\hline Petroclival & Total Excision \\
\hline Foramen magnum & Total Excision \\
\hline Intra orbital & Total Excision \\
Cerebellar Convexity & Subtotal Excision \\
\hline Pineal Region & Total Excision \\
\hline Falx &
\end{tabular}

Table 5: Extent of resection. Simpson grade I: Total excision of tumor+Dura+bone, Total Excision: Total tumor excision and coagulation of dural attachment, Subtotal excision: Not complete excision, debulking

Neuro-navigation was used in all cases of convexity and parasagittal meningiomas.

There were mild to moderate disability in 4 percent ( 6 cases) of all operated cases but there were no surgical related mortalities. 9 patients $(6 \%)$ had regrowth of the tumor, and all these patients had WHO grade I tumor at prior surgeries.

Most common histopathological variety encountered was transitional meningioma, WHO grade I (Table 6).

\begin{tabular}{l|l}
\hline WHO Grade I & \\
\hline Meningothelial meningioma & $22(15 \%)$ \\
\hline Fibrous meningioma & $20(13 \%)$ \\
\hline Transitional meningioma & $42(28 \%)$ \\
\hline Microcystic meningioma & $11(7 \%)$ \\
\hline Psammomatous meningioma & $14(9 \%)$ \\
\hline Clear Cell meningioma & $12(8 \%)$ \\
\hline Angiomatous & $12(8 \%)$ \\
\hline WHO Grade II & \\
\hline Atypical meningioma & $12(8 \%)$ \\
\hline WHO Grade III & $5(3 \%)$ \\
\hline Anaplastic meningioma & \\
\hline
\end{tabular}

Table 6: Histopathological Grading (World Health

Organization classification) 


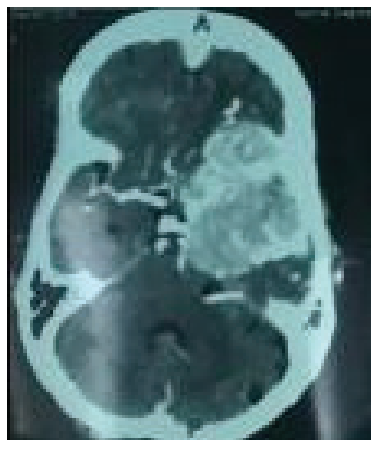

Figure 1a

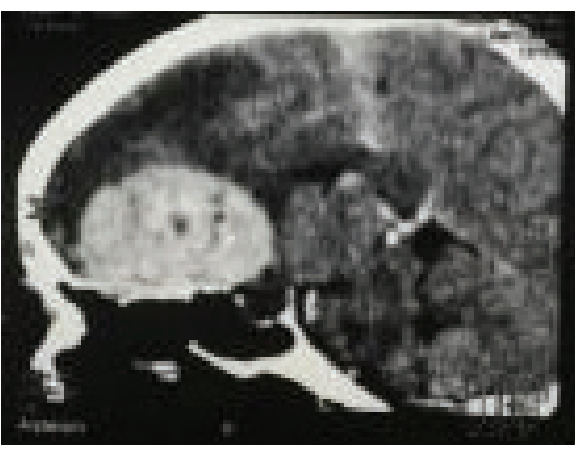

Figure 1b

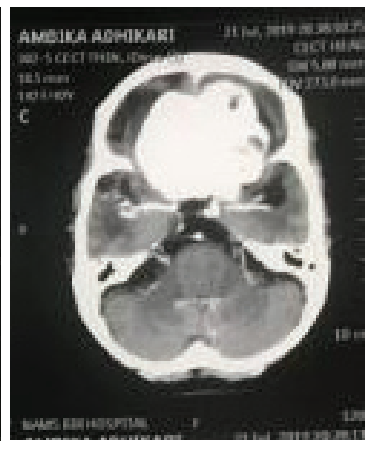

Figure 1c

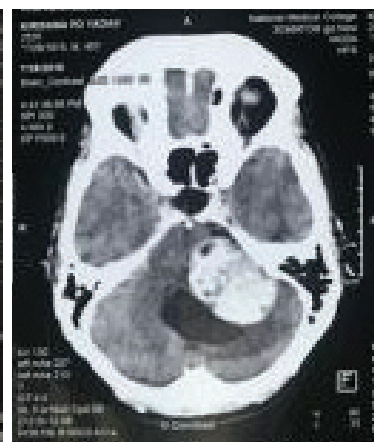

Figure 1d

Figure 1(a,b,c,d): Contrast enhanced CT Scan brain shows avidly enhancement of the tumor with hyperostosis and presence of calcifications. 1a: Sphenoid wing meningioma, 1b: Olfactory groove meningioma, 1c: Giant olfactory groove meningioma, 1d: Left cerebello-pontine meningioma
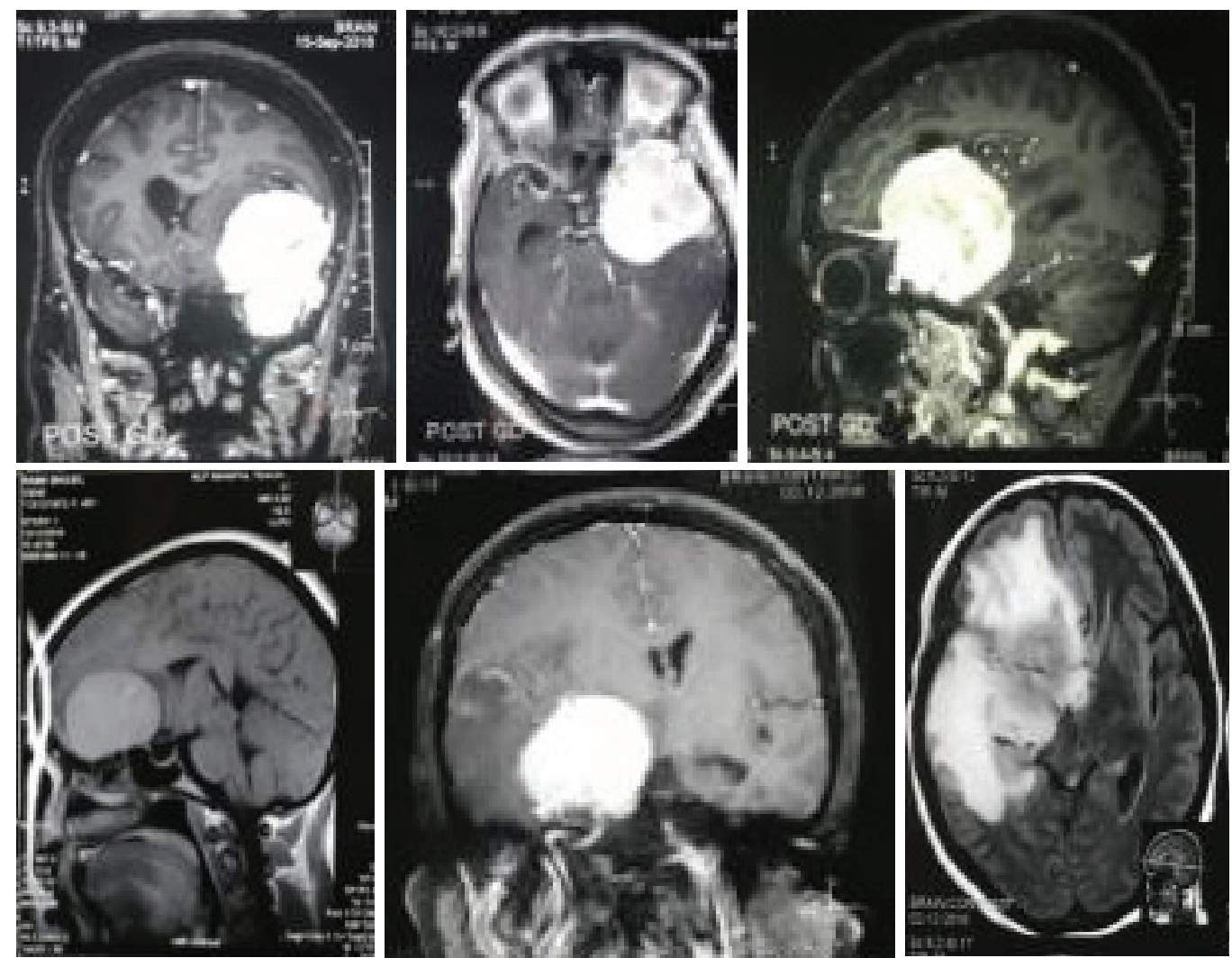

Figure 2: In MRI meningiomas were usually hypo-to isointense relative to the cerebral cortex on T1-weighted sequences and iso- to hyper intense on T2-weighted sequences.
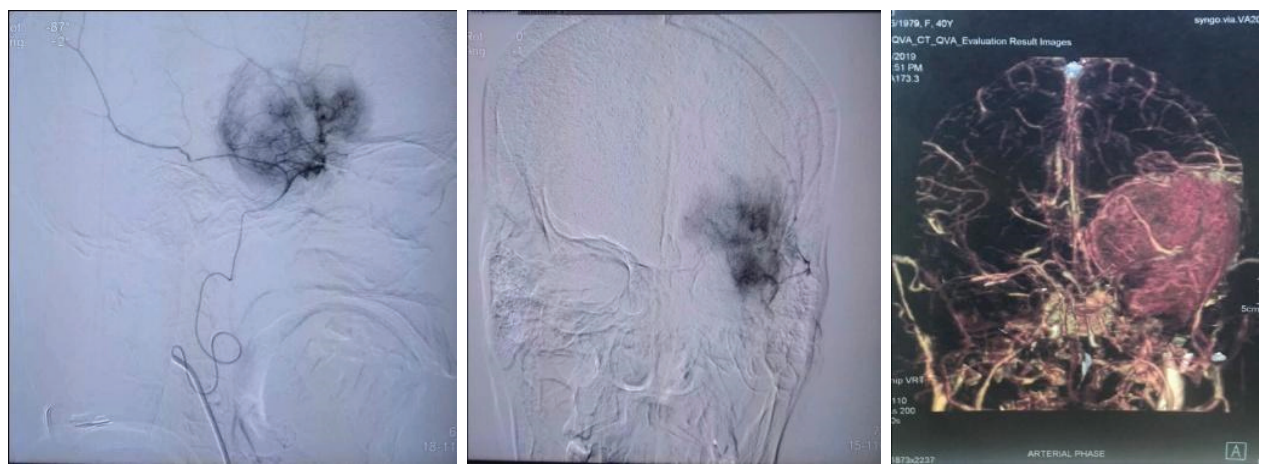

Figure 3. Digital Subtraction angiogram (DSA) and CT angiogram prior to tumor embolization. 


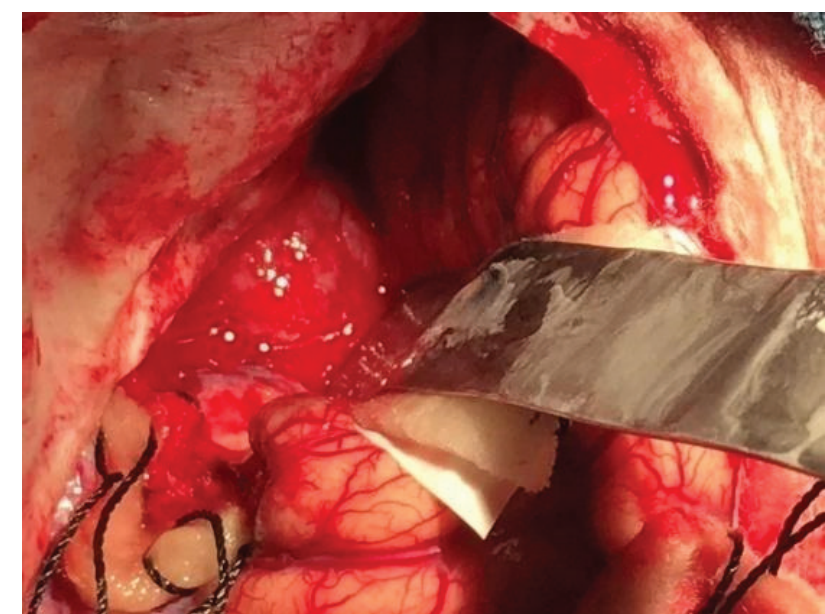

Figure 4a

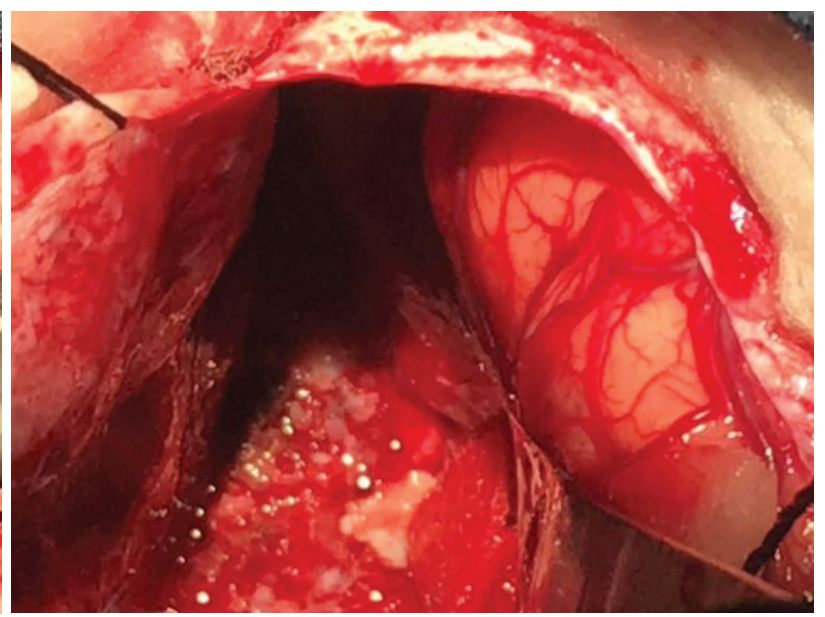

Figure 4b

Figure 4: Intra operative picture of infraorbital meningioma (a) pre-excision (b)post-excision

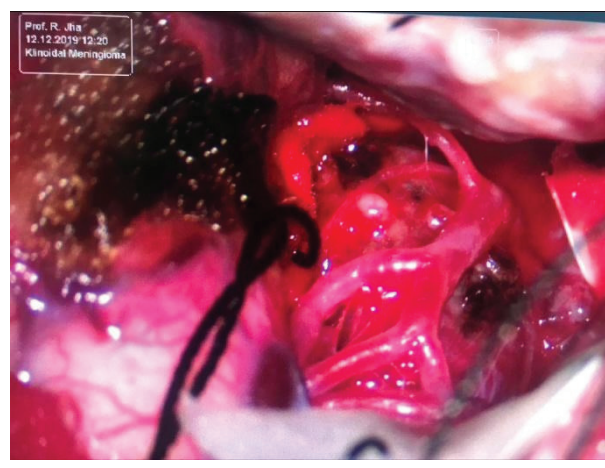

Figure 5a

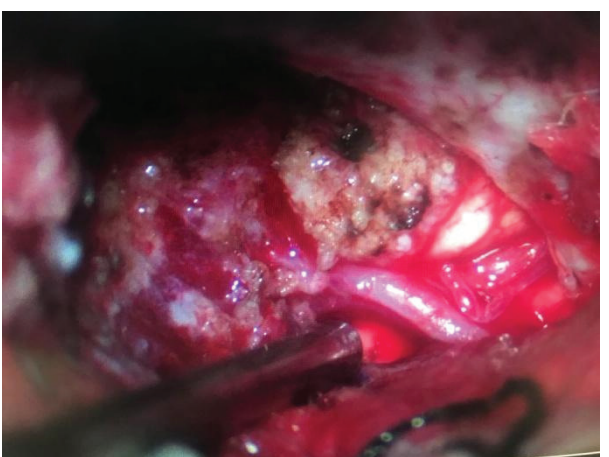

Figure 5b

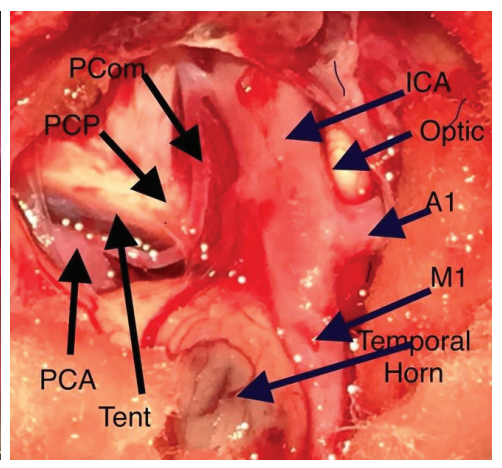

Figure 5b

Figure 5. Intra-operative photo of (a) adherent and surrounding vessels in clinoidal meningioma, (b) middle cerebral artery passing between the tumor, (c) major arteries seen after clinoidal meningioma excision.

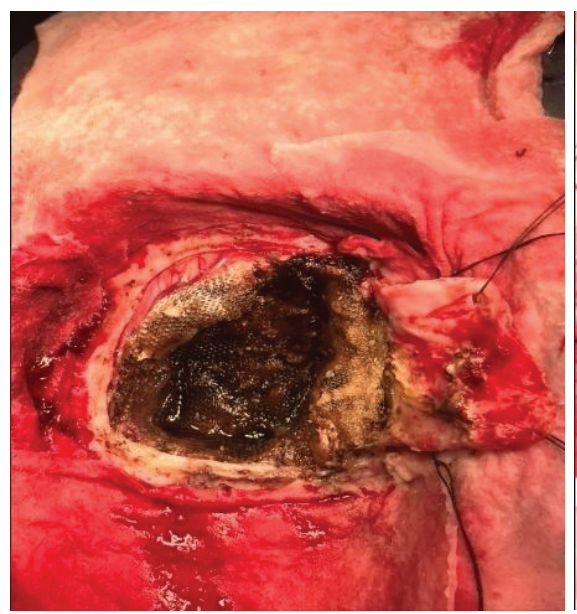

Figure 6a

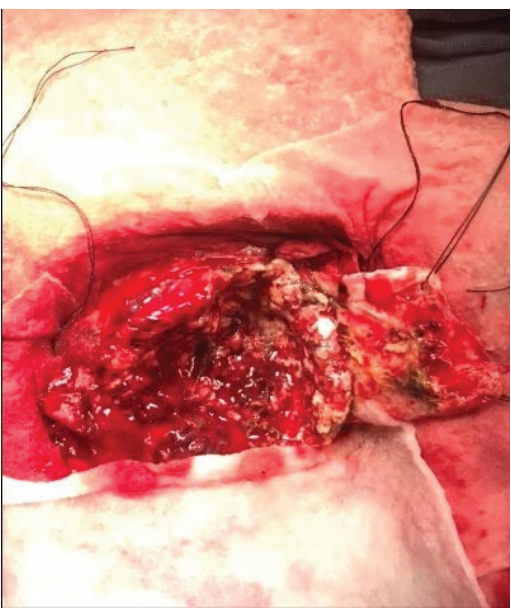

Figure 6b

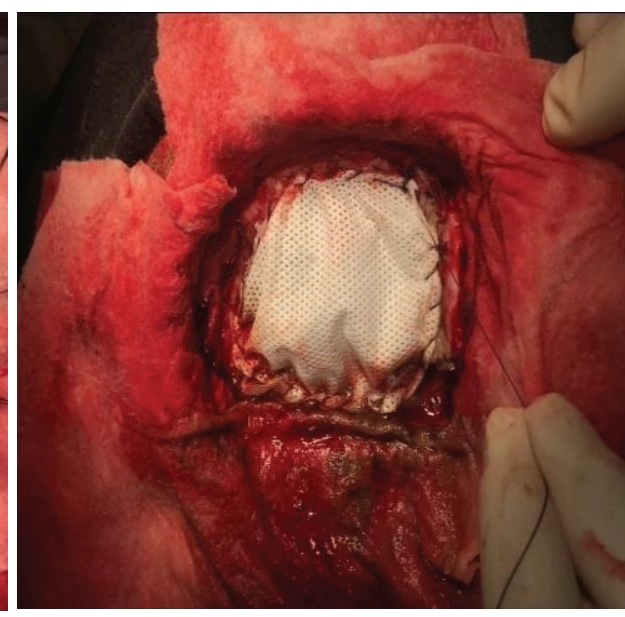

Figure 6c

Figure 6. (a) Tumor debulking, (b) excision, (c) duraplasty 


\section{Clinicopathological characteristics of intracranial meningiomas}
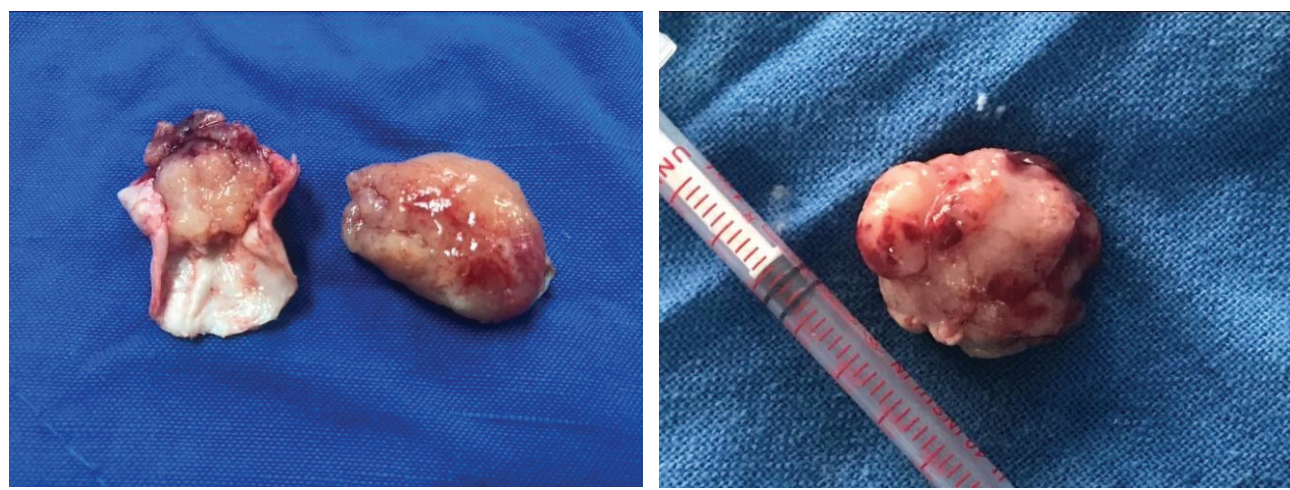

Figure 7: Total tumor excision with dural attachment.
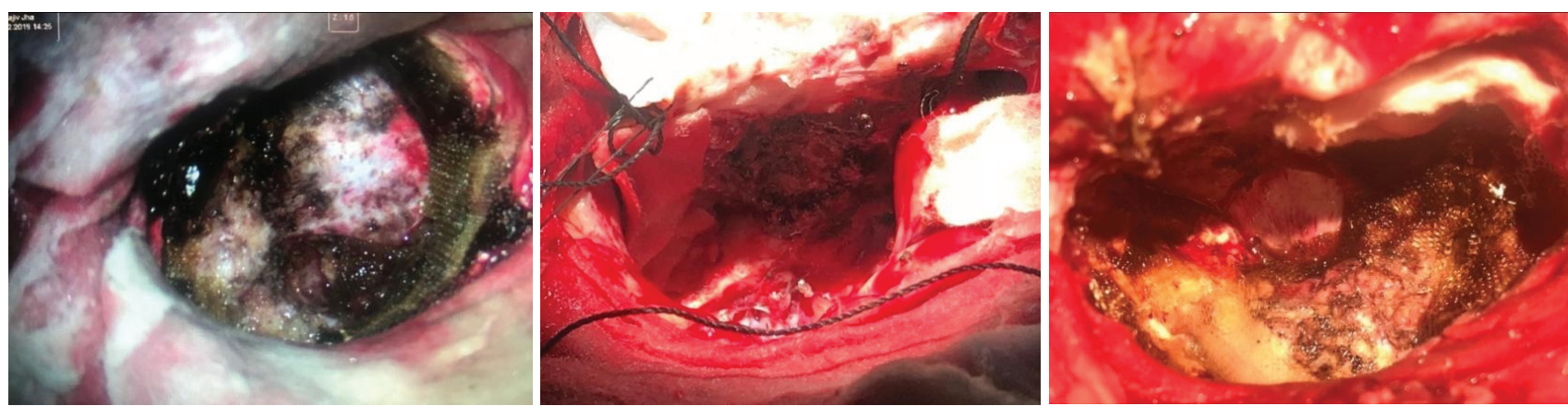

Figure 8: Cavity after total excision and coagulated dural attachment

\section{Discussion}

Meningiomas probably have affected humans since prehistoric times. ${ }^{6,7}$ They are suspected to have been present in pre-Columbian Incas from the Peruvian Andes whose skulls have shown the hyperostosis that can occur with these tumors. Anatomists and pathologists were the first to describe the condition in detail, with one of the best early works being the description by Antoine Louis of "tumeurs fongueuses de la dure-mère" in $1774 .{ }^{8}$ Although initially these tumors were diagnosed and studied exclusively after the patient had died, by the 1800 s surgical removal was being attempted with limited success. With advances in neurological surgery, by the1900s-surgical removal had become the treatment of choice, as demonstrated in the seminal work by Cushing and Eisenhardt published in 1938, the year before Cushing died. ${ }^{6}$ Cushing and Eisenhardt were the first to popularize the term meningioma. ${ }^{9}$

For the first half of this century, diagnosis relied on skull radiographs, cerebral angiography, and pneumoencephalography, which yielded indirect information about the presence, location, and size of these tumors. Direct imaging first became possible in the mid-1960s, with the development of radionuclide brain scanning. Computed tomographic scanning was introduced in the mid-1970s and, with the use of contrast agents, significantly increased the ability to detect small tumors. The introduction of magnetic resonance imaging with contrast agents probably has had only a small additional impact on diagnosis but is rapidly becoming the imaging technique of choice because of excellent anatomic detail and ease of imaging in different planes.

The incidence of meningiomas is approximately 20$25 \%$ of all intra-cranial tumors (the most common nonglial primary intra-cranial tumor), whereas autopsy-based studies indicate an overall incidence of $30 \%$. Furthermore, $2 \%$ of autopsies reveal incidental meningiomas. There is an age-dependent incidence of meningiomas $(0.3 / 100,000$ in childhood and $8.4 / 100,000$ in the elderly). Ninety percent of all meningiomas occur in the supratentorial compartment. ${ }^{10,11,12}$

Intracranial meningiomas are most common in adults in their fourth through sixth decades of life and are rare in children $(2 \%$ of all meningiomas present in childhood). ${ }^{10,11,12,13,14}$

There is a $2: 1$ female to male ratio in intracranial meningiomas. ${ }^{10,11,12,13,14}$ A female preponderance for meningioma correlates with an endogenous hormone level and exogenous hormone replacement in postmenopausal women (in whom an increased incidence of meningioma is seen) as compared with postmenopausal women who have not taken exogenous hormone replacement therapy. ${ }^{15,16}$ Increased growth of meningiomas during 


\section{Jha et al}

pregnancy as well as postpartum clinical regression has been reported but remains poorly understood.

Meningiomas can arise anywhere from the dura, most commonly within the skull and at sites of dural reflection (falx cerebri, tentorium cerebelli, venous sinuses). ${ }^{17}$ Other less common sites include the optic nerve sheath and choroid plexus; approximately 10 percent arise in the spine. Very rarely, meningiomas can arise at extradural sites. $^{18}$

Symptoms from a meningioma are determined by the location of the mass and by the time course over which the tumor develops. Meningiomas frequently are extremely slow growing and often are asymptomatic.

Many meningiomas are asymptomatic or minimally symptomatic, and are discovered incidentally on a neuroimaging study or at autopsy. ${ }^{19,20,21}$ Follow-up studies on patients with asymptomatic meningiomas suggest that most such tumors either remain the same size or grow slowly over prolonged periods. ${ }^{20,21}$

Seizures are present preoperatively in 25 to $40 \%$ of patients who are diagnosed with an intracranial meningioma. ${ }^{22,23}$ In one contemporary series, the median duration of seizures before diagnosis was one month, which is considerably shorter than that observed prior to the availability of CT and MRI. ${ }^{19}$ In one retrospective review, preoperative epilepsy was more common in patients with supratentorial meningiomas, tumors located at the convexity, and tumors associated with severe peritumoral edema. ${ }^{24}$

Visual changes, which are often unrecognized, are common in meningioma. In one series of 80 patients, approximately one-third had symptoms of visual loss, field defects, and/or diplopia. ${ }^{25}$ A cerebellopontine angle meningioma can produce sensorineural hearing loss. Mental status changes with neglect and inattention may result from surprisingly large subfrontal or sphenoid ridge meningiomas. Similar or even larger sized tentorial notch and intraventricular meningiomas are at times asymptomatic and diagnosed incidentally. Meningiomas at different sites can produce characteristic patterns of extremity weakness. A parasagittal meningioma growing on the falx and compressing the motor strip can lead to bilateral leg weakness in the absence of a spinal cord lesion. Foramen magnum meningiomas may produce a subtly progressive sequence of ipsilateral arm, then leg weakness, which is followed by contralateral leg and arm weakness that may be misdiagnosed as multiple sclerosis. Large tumors in the posterior cranial fossa can cause obstructive hydrocephalus, and present with papilledema and classic early morning headache.

Although meningiomas are highly vascularized tumors, symptomatic spontaneous hemorrhage as the initial manifestation of a previously undiagnosed meningioma is extremely rare. ${ }^{26}$

A definitive diagnosis of meningioma and classification as benign, atypical, or malignant (WHO grades I, II, and III, respectively) requires histologic confirmation. However, imaging studies often provide a tentative diagnosis and may be sufficient for treatment when obtaining tissue for pathologic confirmation entails too high a risk of causing further neurologic deficits.

The diagnosis of an intracranial tumor may be suggested by the clinical presentation and is confirmed with magnetic resonance imaging (MRI) or computed tomography (CT). MRI is the preferred imaging modality because it can show the dural origin of the tumor in most cases. The typical meningioma is isointense or hypointense to gray matter on $\mathrm{T} 1$ and isointense or hyperintense on proton density and T2 weighted images; there is strong homogeneous enhancement with gadolinium. Most meningiomas show a characteristic marginal dural thickening that tapers peripherally (the "tail" sign)

On CT, the typical meningioma is a well-defined extra-axial mass that displaces the normal brain. They are smooth in contour, adjacent to dural structures, and sometimes calcified or multilobulated. Iso-intensity with a normal surrounding brain may make diagnosis difficult on a non-contrasted scan, but intravenous contrast administration results in uniformly bright enhancement. Secondary involvement of adjacent bone (reactive sclerosis, invasion, erosion) is uncommon with convexity meningiomas, but occurs in up to one-half of skull base tumors. ${ }^{27}$

Although results from positron emission tomography (PET) may predict the aggressiveness of a meningioma and the potential for recurrence, ${ }^{28}$ PET is not routinely used since maximal surgical resection is the goal for all grades of meningioma.

Other disease processes can involve the dura or subdural space, resulting in an appearance on MRI or CT that may suggest meningioma. These include lymphoma, metastatic carcinoma, inflammatory lesions such as sarcoidosis and Wegener's granulomatosis, and infections such as tuberculosis. ${ }^{17,29,30}$

Treatment of meningiomas is dependent on the tumor size, tumor location, associated symptoms, age, and health status. Asymptomatic lesions can be observed with close monitoring of clinical and disease status. A tentative diagnosis of meningioma can be made on classic radiographic findings (with MRI scans preferred) of a dural based mass, homogeneous contrast enhancement, the presence of a dura tail, or a cerebrospinal fluid cleft. Octreotide scintigraphy can be used as an adjunct when there is uncertainty in the diagnosis. This is especially true 
for skull-based tumors, optic nerve sheath tumors, and for identifying recurrent tumors versus scar tissue ${ }^{31,32}$

For symptomatic or progressively enlarging meningiomas, complete surgical excision, when feasible, of the tumor bulk, surrounding dural attachment, and involved bone is recommended ${ }^{33}$ Most convexity, spinal, and falcine meningiomas are amenable to complete excision. In contrast, meningiomas involving the cavernous sinus, petroclival region, posterior region of the superior sagittal sinus, or optic nerve sheath and parasagittal meningiomas involving the sinus posterior to the coronal sinus have a much higher morbidity rate $34,35,36$ If complete excision is not possible, options include definitive external-beam radiation and partial excision followed by adjuvant radiotherapy. Long-term data using definitive external-beam radiation have demonstrated prolonged tumor control comparable with that observed with surgery followed by adjuvant radiation ${ }^{37}$

Intensity modulated radiation therapy (IMRT) is being investigated in a phase II Radiation Therapy Oncology Group (RTOG 0539, NCT00895622) study. Patients with meningiomas are being stratified into three recurrence risk groups based on WHO grade, extent of resection, and recurrence status. Group I patients have a low risk for recurrence, with newly diagnosed WHO grade I meningioma that has been either subtotally or gross totally resected. Group II patients have an intermediate risk, with a newly diagnosed WHO grade II meningioma after gross resection or recurrent WHO grade I meningioma. Group III patients have a high risk and include those with WHO grade III meningiomas, recurrent WHO grade II meningiomas, and newly diagnosed subtotally resected WHO grade II meningiomas. Group I patients will be observed, group II patients will receive 50 Gy of IMRT, and group III patients will receive 60 Gy of IMRT.

Stereotactic radiotherapy (SRS) has become an alternative option to external-beam radiation for recurrent or partially resected meningiomas $35 \mathrm{~mm}$ in diameter and for patients in whom surgery is not an option because of the tumor's location or patient comorbidities $38,39,40,41$

Alternative therapies have been investigated, especially for inoperable meningiomas, recurrent disease, and aggressive histologies. Based on the high prevalence of elevated progesterone receptor expression in meningiomas and promising results in smaller studies, mifepristone (RU486) was investigated in a prospective multicenter study with disappointing results. ${ }^{42,43,44}$

Chemotherapeutic agents have been investigated and most have failed to show consistent efficacy with the possible exceptions of hydroxyurea and a multidrug regimen of cyclophos- phamide, doxorubicin, and vincristine (CAV).
Interferon and somatostatin analogs are among the biologic agents showing responses in patients with recurrent meningioma. Six patients with recurrent and unresectable meningiomas that had been previously irradiated were treated with IFN- $\alpha-2 B$ at $4 \mathrm{mU} / \mathrm{m} 2$ per day, 5 days per week. Four patients had disease stabilization and one patient had a slight regression; responses lasted 6-14 months. ${ }^{45}$

Newer molecular targets including the PDGF, VEGF, EGFR, phosphoinositide 3-kinase/Akt, and Ras/Raf/ mitogen- activated protein kinase pathways are being evaluated in meningiomas. Although initial studies with imatinib, a PDGF inhibitor, in recurrent meningiomas have not shown significant activity, a phase II study combining imatinib with hydroxyurea has closed with results expected to be released shortly. ${ }^{46}$

\section{Conclusion}

Intracranial meningiomas are slow growing extraaxial tumors, usually benign, which are most commonly located along convexities, sphenoid ridge and parasagittal area. Most are cured if completely removed, which is not always possible. Common histological grading was Grade I, transitional type tumor.

\section{Acknowledgement}

The authors would like to thank the patients and their relatives for providing consent to publish this article. The authors would also like to thank all the residents and staffs at the department of neurosurgery, NAMS Bir Hospital for their help during collecting the details to work and publish this article.

\section{Conflict of Interest: None Source(s) of support: None}

\section{References}

1. Alyamany M, Alshardan MM, Jamea AA, ElBakry N, Soualmi L, Orz Y. Meningioma Consistency: Correlation Between Magnetic Resonance Imaging Characteristics, Operative Findings, and Histopathological Features. Asian J Neurosurg. 2018;13(2):324-8. https://doi.org/10.4103/17935482.228515

2. Ostrom QT, Gittleman H, Farah P, et al. CBTRUS statistical report: Primary brain and central nervous system tumors diagnosed in the United States in 2006-2010 [published correction appears in Neuro Oncol. 2014 May;16(5):760]. Neuro Oncol. 2013;15 
Suppl 2(Suppl 2):ii1-ii56. http://doi.org/10.1093/ neuonc/not151

3. Nakasu S, Nakasu Y, Fukami T, Jito J, Nozaki $\mathrm{K}$. Growth curve analysis of asymptomatic and symptomatic meningiomas. J Neurooncol. 2011;102(2):303-10. https://doi.org/10.1007/s11060010-0319-1

4. Yoneoka Y, Fujii Y, Tanaka R. Growth of incidental meningiomas. Acta Neurochir (Wien). 2000;142(5):507-11.https://doi.org/10.1007/ s007010050463

5. Whittle IR, Smith C, Navoo P, Collie D. Meningiomas. Lancet. 2004;363(9420):1535-43. http://doi.org.:10.1016/S0140-6736(04)16153-9

6. Cushing $\mathrm{H}$, Eisenhardt L. Meningiomas: their classification, regional behavior, life history, and surgical end results. Baltimore: Charles C Thomas, 1938. http://doi.org/10.1002/18002610438

7. Al-Rodan NRF, Laws ER Jr. Meningioma: a historical study of the tumor and its surgical management. Neurosurgery 1990; 26:832-47.

8. Louis A. MCmoire sur les tumeurs fongueuses de la dre-msre. Me'rnoires. Acade'rnie Royale de Chirurgie (Paris). 1774; 5: 1-59.

9. Cushing $\mathrm{H}$. The meningiomas (dural endotheliomas): their source, and favoured seats of origin (Cavendish Lecture). Brain. 1922; 45:282-316. http://doi. org:10.1093/45.2.282

10. Bondy M, Ligon BL: Epidemiology and etiology of intracranial meningiomas: a review. J Neurooncol. 1996; 29:197-205.

11. De Monte F. Current management of meningiomas. Oncology (Williston Park). 1995;9(1):83-101.

12. Longstreth WT Jr, Dennis LK, McGuire VM, Drangsholt MT, Koepsell TD. Epidemiology of intracranialmeningioma. Cancer.1993;72(3):639-48. 10.1002/1097-0142(19930801)72:3<639::aidcncr2820720304>3.0.co;2-p

13. Sanson M, Cornu P: Biology of meningiomas. Acta Neurochir(Wein). 2000; 142:493-505. http://doi. org/ 10.3171/FOC-07/10/E1

14. Wilson CB. Meningiomas: genetics, malignancy, and the role of radiation in induction and treatment. The Richard C. Schneider Lecture. J Neurosurg. 1994;81(5):666-75.http://doi.org/10.3171/ jns.1994.81.5.0666

15. Claus EC, Black PM, Bondy ML, Calvocoressi L, Schildkraut JM,Wiemels JL, et al: Exogenous hormone use and meningioma risk. Cancer. 2007; 110:471-6. http://doi.org/10.3171/FOC-07/10/E1

16. Jhawar BS, Fuchs CS, Colditz GA, Stampfer MJ. Sex steroid hormone exposures and risk formeningioma. J Neurosurg. 2003;99(5):848-53. http://doi.org /10.3171/jns.2003.99.5.0848

17. Whittle IR, Smith C, Navoo P, Collie D. Meningiomas. Lancet. 2004;363(9420):1535-43. http://doi.org/10.1016/S0140-6736(04)16153-9

18. Rai R, Iwanaga J, Shokouhi G, Oskouian RJ, Tubbs RS. The Tentorium Cerebelli: A Comprehensive Review Including Its Anatomy, Embryology, and Surgical Techniques. Cureus. 2018;10(7): e3079. http://doi.org/10.7759/cureus.3079

19. Vernooij MW, Ikram MA, Tanghe HL, et al. Incidental findings on brain MRI in the general population. N Engl J Med. 2007; 357:1821. http:// doi.org/10.1056/070972

20. Annegers JF, Schoenberg BS, Okazaki H, Kurland LT. Epidemiologic Study of Primary Intracranial Neoplasms. Arch Neurol. 1981;38(4):217-9. http:// doi.org:10.1001/ archneur.1981.00510040043006

21. Nakasu S, Hirano A, Shimura T, Llena JF. Incidental meningiomas in autopsy study. Surg Neurol. 1987;27(4):319-22.http://doi.org/10.1016/00903019(87)90005-x

22. Niiro M, Yatsushiro K, Nakamura K, Kawahara Y, Kuratsu J. Natural history of elderly patients with asymptomatic meningiomas. J Neurol Neurosurg Psychiatry. 2000;68(1):25-8. http://doi.org/10.1136/ jnnp.68.1.25

23. Go RS, Taylor BV, Kimmel DW. The natural history of asymptomatic meningiomas in Olmsted County, Minnesota. Neurology. 1998;51(6):1718-20. http:// doi.org/10.1212/wnl.51.6.1718

24. Chozick BS, Reinert SE, Greenblatt SH. Incidence of seizures after surgery for supratentorial meningiomas: a modern analysis. J Neurosurg. 1996;84(3):382-6. http://doi.org/10.3171/jns. 1996.84.3.0382

25. Lieu AS, Howng SL. Intracranial meningiomas and epilepsy: incidence, prognosis and influencing factors. Epilepsy Res. 2000;38(1):45-52. http://doi. org/10.1016/s0920-1211(99)00066-2

26. Anderson D, Khalil M. Meningioma and the ophthalmologist. A review of 80 cases. Ophthalmology. 1981;88(10):1004-9. http:// doi.org/10.1016/s0161-6420(81)80028-0

27. Bosnjak R, Derham C, Popović M, Ravnik J. Spontaneous intracranial meningioma bleeding: clinicopathological features and outcome. J Neurosurg. 2005;103(3):473-84. doi:10.3171/ jns.2005.103.3.0473

28. Pieper DR, Al-Mefty O, Hanada Y, Buechner D. Hyperostosis associated with meningioma of the cranial base: secondary changes or tumor invasion. Neurosurgery. 1999;44(4):742-7. http:// doi.org/10.1097/00006123-199904000-00028 
29. Weber DC, Lovblad KO, Rogers L. New pathology classification, imagery techniques and prospective trials for meningiomas: the future looks bright. Curr Opin Neurol. 2010;23(6):563-70. http://doi. org/10.1097/WCO.0b013e328340441e

30. Johnson MD, Powell SZ, Boyer PJ, Weil RJ, Moots PL. Dural lesions mimicking meningiomas. Hum Pathol.2002;33(12):1211-26. http://doi.org/10.1053/ hupa.2002.129200

31. Bohuslavizki KH, Brenner W, Braunsdorf WE, et al. Somatostatin receptor scintigraphy in the differential diagnosis of meningioma. Nucl Med Commun. 1996;17(4):302-10. http://doi. org/10.1097/00006231-199604000-00157

32. Saeed P, Tanck MW, Freling N et al. Soma- tostatin receptor scintigraphy for optic nerve sheath meningiomas. Ophthalmology 2009; 116:1581-6. http://doi.org/10.1634/theoncologist.2011-0193

33. Simpson D. The recurrence of intracranial meningiomas after surgical treatment. J Neurol Neurosurg Psychiatry. 1957;20(1):22-39. http://doi. org/10.1136/jnnp.20.1.22

34. Black PM, Villavicencio AT, Rhouddou C, Loeffler JS. Aggressive surgery and focal radiation in the management of meningiomas of the skull base: preservation of function with maintenance of local control. Acta Neurochir (Wien). 2001;143(6):555-62.http://doi.org/10.1007/ s007010170060

35. O'Sullivan MG, van Loveren HR, Tew JM Jr. The surgical resectability of meningiomas of the cavernous sinus. Neurosurgery. 1997;40(2):238-47.

36. Roberti F, Sekhar LN, Kalavakonda C, Wright DC. Posterior fossa meningiomas: surgical experience in 161 cases. Surg Neurol. 2001;56(1):8-21. http://doi. org/ 10.1016/s0090-3019(01)00479-7

37. Debus J, Wuendrich M, Pirzkall A, et al. High efficacy of fractionated stereotactic radiotherapy of large base-of-skull meningiomas: long-term results. J Clin Oncol. 2001;19(15):3547-53. http:// doi.org/ 10.1200/JCO.2001.19.15.3547
38. Black PM. Hormones, radiosurgery and virtual reality: New aspects of meningioma management. Can J Neurol Sci. 1997;24:302-6. http://doi.org/ 10.1017/S0317167100032960

39. Flickinger JC, Kondziolka D, Maitz AH, Lunsford LD. Gamma knife radiosurgery of imagingdiagnosed intracranial meningioma. Int $\mathbf{J}$ Radiat Oncol Biol Phys. 2003;56(3):801-6. doi:10.1016/ s0360-3016(03)00126-3

40. Morita A, Coffey RJ, Foote RL, Schiff D, Gorman D. Risk of injury to cranial nerves after gamma knife radiosurgery for skull base meningiomas: experience in 88 patients. J Neurosurg. 1999;90(1):42-9. http:// doi.org/10.3171/jns.1999.90.1.0042

41. Ojemann SG, Sneed PK, Larson DA, et al. Radiosurgery for malignant meningioma: results in 22 patients. J Neurosurg. 2000;93 Suppl 3:62-7. http://doi.org/10.3171/jns.2000.93.supplement

42. Grunberg SM, Weiss MH, Spitz IM, et al. Treatment of unresectable meningiomas with the antiprogesterone agent mifepristone. J Neurosurg. 1991;74(6):861-6. http://doi.org/10.3171/jns.1991.74.6.0861

43. Lamberts SW, Tanghe HL, Avezaat CJ, et al. Mifepristone (RU 486) treatment of meningiomas. Neurosurg Psychiatry. 1992;55(6):486-90. http:// doi.org/10.1136/jnnp.55.6.486

44. Ji Y, Rankin C, Grunberg S, et al. Double-Blind Phase III Randomized Trial of the Antiprogestin Agent Mifepristone in the Treatment of Unresectable Meningioma: SWOG S9005. J Clin Oncol. 2015;33(34):4093-8.http://doi.org/10.1200/ JCO.2015.61.6490

45. Kaba SE, DeMonte F, Bruner JM, et al. The treatment of recurrent unresectable and malignant meningiomas with interferon alpha-2B. Neurosurgery. 1997;40(2):271-5. http://doi.org/10.1097/00006123199702000-00007

46. Wen PY, Yung WK, Lamborn KR, et al. Phase II study of imatinib mesylate for recurrent meningiomas (North American Brain Tumor Consortium study 0108). Neuro Oncol. 2009;11(6):853-60. http://doi. org/10.1215/15228517-2009-010 